\title{
Erratum to: Ciliary Neurotrophic Factor Inhibits Bone Formation and Plays a Sex-Specific Role in Bone Growth and Remodeling
}

\author{
Narelle E. McGregor • Ingrid J. Poulton • Emma C. Walker • \\ Sueli Pompolo • Julian M. W. Quinn • T. John Martin • \\ Natalie A. Sims
}

Published online: 15 March 2013

(c) Springer Science+Business Media New York 2013

\section{Erratum to: Calcif Tissue Int (2010) 86:261-270 \\ DOI 10.1007/s00223-010-9337-4}

It has recently come to our attention that our original publication contains some incorrect information. We reported that murine recombinant Ciliary Neurotrophic Factor (CNTF) and murine Cardiotrophin-Like Cytokine (CLC) were used for our in vitro studies, but human CNTF and CLC were used. Recombinant murine CNTF and CLC are not commercially available.

To correct this error, the following changes are needed:

1. On page 262 the statement that "mCNTF, mCLC (R\&D Systems), or mNP (Chemicon, Temecula, CA)" were used for our cell culture studies should read: "hCNTF, hCLC, or mNP (all from R\&D Systems)".

2. Later on the same page, the statement that "then $10 \mathrm{ng} /$ $\mathrm{ml}$ mCNTF, mCLC, or mNP" were added should read: "then hCNTF, hCLC or mNP" were added.

3. Finally, on page 263 where we stated "Cells were treated with RANKL and M-CSF (R\&D Systems) $\pm 10 \mathrm{ng} / \mathrm{ml}$ mCNTF" should read: "Cells were treated with RANKL and M-CSF (R\&D Systems) $\pm 10 \mathrm{ng} / \mathrm{ml} \mathrm{hCNTF”.}$

The online version of the original article can be found under doi:10.1007/s00223-010-9337-4.

N. E. McGregor · I. J. Poulton · E. C. Walker · S. Pompolo ·

J. M. W. Quinn - T. J. Martin · N. A. Sims

St. Vincent's Institute, 9 Princes Street, Fitzroy, VIC 3065,

Australia

J. M. W. Quinn · T. J. Martin · N. A. Sims ( $\square)$

Department of Medicine, St. Vincent's Hospital, The University

of Melbourne, Fitzroy, VIC 3065, Australia

e-mail: nsims@svi.edu.au

Present Address:

J. M. W. Quinn

Monash Medical Centre, Prince Henry's Institute, Level 4, Block

E, 246 Clayton Road, Clayton, VIC 3168, Australia 